\title{
The Development of Learning Resource for the Saleng Community under the Bridge of Zone 1 Entitled "How to Repair Electrical Appliances"
}

\author{
Pornpapatsorn Princhankol, Kuntida Thamwipat, Paveena Thambunharn, Wuttipong Phansatarn \\ Faculty of Industrial Education and Technology \\ King Mongkut's University of Technology Thonburi \\ Bangkok, Thailand
}

\begin{abstract}
This research was aimed to develop a learning resource for the Saleng community under the bridge of zone 1 entitled "How to Repair Electrical Appliances" in order to determine the quality of learning community and to examine the satisfaction of the sampling group which was chosen using specified sampling method. The tools used in this study consisted of 1) learning resource for the Saleng community under the bridge of zone 1 entitled "How to Repair Electrical Appliances", including video clips, posters, leaflets, and exhibitions; 2) the quality assessment forms; and 3) the satisfaction evaluation form. According to the quality assessment of the learning resource for the Saleng community under the bridge of zone 1 by the panel of 6 experts, the mean score for the quality in terms of contents was 4.83 with S.D. of 0.29 , or at a very good level. As for the quality in terms of media, the mean score was 4.47 with S.D. of .63, or at a good level. Afterwards, the learning resource for the Saleng community under the bridge of zone 1 entitled "How to Repair Electrical Appliances" was used by the sampling group of 30 persons. The satisfaction towards the learning resource was 4.71 with S.D. of .64, or at the highest level. It could be concluded that the learning resource for the Saleng community under the bridge of zone 1 entitled "How to Repair Electrical Appliances" can be used as a practical instructional tool for the community.
\end{abstract}

Keywords-learning resource; Saleng community under the bridge of zone 1; repairing electrical appliances

\section{INTRODUCTION}

The communities under the bridge in many parts of Bangkok are places where many homeless lived. Bangkok Metropolitan Administration and National Housing Agency have collaborated to provide over 700 families of these people with 3 plots of land which are not far from their previous places. These are the community under the bridge at PrachaUtit 76, Toong-kru District (Zone 1), the community under the bridge at Poonsarp, Saimai District (Zone 2) and the community under the bridge at Onnuch, Prawate District (Zone 3 ). The community under the bridge of zone 1 is located at Pracha-Utit Road Soi 76, Toong-kru District, Bangkok which is about 10 kilometres away from King Mongkut's University of Technology Thonburi. This 13-rai* (*1 rai is equal to 1,600 square metres) plot of land houses 182 families at the moment. There are public areas such as sports field, playground, and pre-school development centre to hold meetings and activities among family members. The majority of people or over $70 \%$ of them work as itinerant junk buyers, in other words, they buy and collect unwanted or faulty electrical appliances, litter, empty plastic bottles, paper and the like and then they classify and sell them later. The majority of people are poor and their educational level was not high. They use saleng or threewheeled pedal cart as their vehicle and as such, their community is sometimes called "Saleng Community" which is one of many disadvantaged communities in Thailand.

In 2011, King Mongkut's University of Technology Thonburi (KMUTT) conducted the research study entitled "Community Research Project to Reduce and Solve the Social Inequality in Bangkok: A Case Study of Community under the Bridge of Zone 1, Toong-kru District, Bangkok" [1] with National Institute of Development Administration and Bangkok Metropolitan Administration in order to examine and analyse the current situations and requirements of the community. The results from this research included 15 developmental policy plans which had been amended by the community commission and the community people.

Recently, from August 2012 to January 2013, the researchers have participated in the project entitled "GoodHearted Vocation Teacher to Support Itinerant Junk Buyers", which was funded by Siam Commercial Bank PLC in order to improve the living quality of those people. In this project, teachers from electrical and automobile departments as well as recycling specialists have taught the community members so that they could apply the knowledge to their profession. The research outcome shows that the community expressed their satisfaction at a high level and such research project was the first runner up of the national SCB Challenge Community Project Award granted by Siam Commercial Bank PLC [2]. The committee recognises the importance of community development with the aim that the community will develop continuously and that the demands of the community members under the bridge of zone 1 will be met as a way to enhance and extend the above-mentioned research project entitled "Community Research Project to Reduce and Solve the Social Inequality in Bangkok: A Case Study of Community under the Bridge of Zone 1, Toong-kru District, Bangkok".

Therefore, the researchers would like to develop the learning resource for the Saleng community under the bridge of zone 1 entitled "How to Repair Electrical Appliances" (how to repair fans, irons and rice cookers) so that there is a learning centre for the community. In this project, the researchers 
developed video clips entitled "How to Repair Electrical Appliances", posters to provide them with knowledge about how to maintain electrical appliances, exhibition about the history of the local community and leaflets with information about the community so that the community members could use this knowledge to support their career by repairing electrical appliances to increase the value of old junk, resulting in more income for the community members. Moreover, the exhibition about the history of the local community and the leaflets would become the centre of attention for those interested and visitors to know more about the community.

\section{RESEARCH METHODOLOGY}

\section{A. Research Objectives}

1) To develop a learning resource for the Saleng community under the bridge of zone 1 entitled "How to Repair Electrical Appliances"

2) To assess the quality of the learning resource for the Saleng community under the bridge of zone 1 entitled "How to Repair Electrical Appliances"

3) To examine the users' satisfaction towards the learning resource for the Saleng community under the bridge of zone 1 entitled "How to Repair Electrical Appliances"

\section{B. Research Hypotheses}

1) The quality of the learning resource for the Saleng community under the bridge of zone 1 entitled "How to Repair Electrical Appliances" would be at a high level.

2) The users would express their satisfaction towards the learning resource for the Saleng community under the bridge of zone 1 entitled "How to Repair Electrical Appliances" at a high level.

\section{Expected Outcomes}

1) There would be a learning resource for the Saleng community under the bridge of zone 1 entitled "How to Repair Electrical Appliances" with a high level of quality.

2) The learning resource for the Saleng community under the bridge of zone 1 entitled "How to Repair Electrical Appliances" could help the community members to repair the electrical appliances.

3) The research could be used as a model to develop a learning resource for other communities.

\section{RESEARCH SCOPE}

\section{A. Contents in the Learning Resource}

The contents in the learning resource for the Saleng community under the bridge of zone 1 entitled "How to Repair Electrical Appliances" would include an introduction to the tools for repair, how to repair fans, irons, rice cookers according to the conditions, and how to maintain electrical appliances. There would also be an exhibition about the history of the community and the leaflets with information of the community.

\section{B. Population and Sampling Group}

The population in this study consisted of 500 persons who live in the Saleng community under the bridge of zone 1 [3].

The sampling group in this study consisted of 30 persons who worked as itinerant junk buyers or Saleng pedal cart riders. They were chosen using specified sampling method out of those who previously participated in the research entitled "Good-Hearted Vocation Teacher to Support Itinerant Junk Buyers".

\section{Expert Panel}

The expert panel consisted of those who have skills and knowledge about how to assess the development of the learning resource for the Saleng community under the bridge of zone 1 . They were chosen using specified sampling method. They had qualifications and they were voluntary to be in the expert panel of this research.

1) Experts in media: Experts in media ere those with at least a Masters degree or at least five years of working experiences. They have knowledge, experiences and skills in the development of learning resources, media production, publishing industry, print design, colour scheme and proofreading in order to assess the quality of the learning resource for the Saleng community under the bridge of zone 1 in terms of media. There were three experts in media.

2) Experts in contents: Experts in contents were those with at least a Masters degree or at least five years of working experiences. They have knowledge and understanding about steps and procedure to repair electrical appliances, which in this case are fans, irons, and rice cookers, and about the history of the community. There were three experts in contents.

\section{TOOLS IN THIS RESEARCH}

The tools used in this research for the development of the learning resource for the Saleng community under the bridge of zone 1 were as follows:

\section{A. The Learning Resource}

- Video clips entitled "How to Repair Electrical Appliances"

- Posters about how to maintain electrical appliances

- Exhibition about the history of the community

- Leaflets about the information of the community

B. The Quality Assessment Form

- The quality in terms of contents with Likert's 5-rating scale

- The quality in terms of media with Likert's 5-rating scale

\section{The Satisfaction Evaluation Form}

- The satisfaction evaluation form for the sampling group with 5-rating scale 


\section{PROCEDURE FOR TOOL DEVELOPMENT}

\section{A. The Development of the Learning Resource}

The development of the learning resource for the Saleng community under the bridge of zone 1 began with (1) the identification of media format and genre and (2) the specification of the learning resource based on the demands of the community. The outcome was that the community would like to see the learning resource as a way to learn more entitled "How to Repair Electrical Appliances".

\section{B. Research Plan and Development}

1) The research objectives of the learning resource for the Saleng community under the bridge of zone 1 were identified.

2) The research scope and the preliminaries were determined.

3) The research duration was set.

\section{Development according to ADDIE Model}

1) Stage 1 Analysis: The learning resource for the Saleng community under the bridge of zone 1 was aimed to address the need of the community. Therefore, the demands of the community needed to be analysed and surveyed in terms of the topics, the information of the community and the location for the learning resource. According to the resolve from the analysis and survey, the community members would like to have the topics to cover how to fix fans, irons and rice cookers. As for the information about the community, according to the interview with the community committee and Toong-kru Office, it was agreed that Dutdao-Learning Centre Building would be used as the location for this research.

2) Stage 2 Design: The data were gathered and summarised in the form of dummy table which included the topics in the learning resource for the Saleng community under the bridge of zone 1 entitled "How to Repair Electrical Appliances". Afterwards, it would be assessed by the expert panel and revised accordingly.

3) Stage 3 Development: After a conclusion was reached, many drafts would be drawn about the contents. The data and the articles as well as the information of the community would be gathered in order to create video clips, posters, exhibition material and leaflets. Another dummy table would be drawn and assessed by the expert panel before the implementation in the next stage.

4) Stage 4 Implementation: The software was chosen for the development of the learning resource for the Saleng community under the bridge of zone 1 entitled "How to Repair Electrical Appliances”. Many applications were needed and these included software for magazine publication, image editing, graphic design, video editing and digital magazine before we could develop the learning resource for the Saleng community under the bridge of zone 1 entitled "How to Repair Electrical Appliances".

5) Stage 5 Evaluation: The expert panel was invited to the learning centre of the Saleng community under the bridge of zone 1 in order to assess the learning resource entitled "How to Repair Electrical Appliances" in terms of media production, contents and quality. They were six experts in total. The learning resource would be revised according to the suggestions and comments by the expert panel in order to improve the quality, contents and media production.

\section{Test or Experiment}

The learning resource for the Saleng community under the bridge of zone 1 entitled "How to Repair Electrical Appliances" was used by 30 itinerant junk buyers who were chosen using specified sampling method. Afterwards, they filled out the questionnaire and the data would be analysed.

\section{E. Analysis}

The data would be analysed to improve from the learning resource for the Saleng community under the bridge of zone 1 entitled "How to Repair Electrical Appliances".

\section{RESEARCH RESULTS}

The learning resource for the Saleng community under the bridge of zone 1 entitled "How to Repair Electrical Appliances" was developed and contained the following aspects: video clips, posters, leaflets and exhibition. These were shown in the figures below.

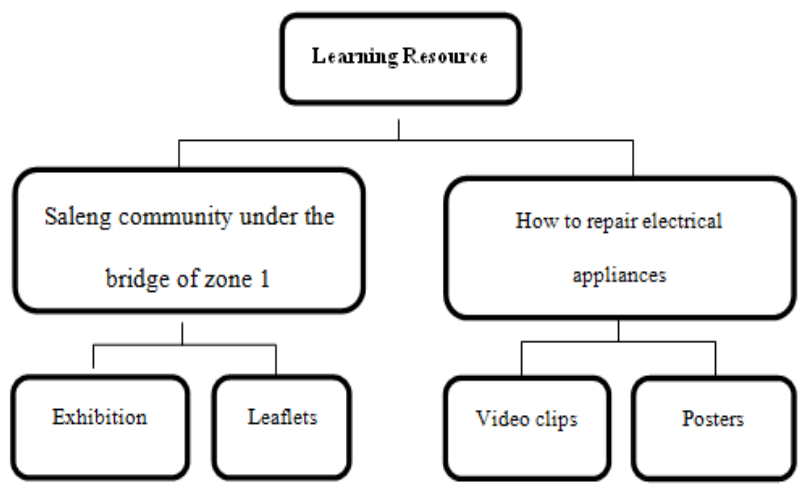

Fig. 1. The learning resource
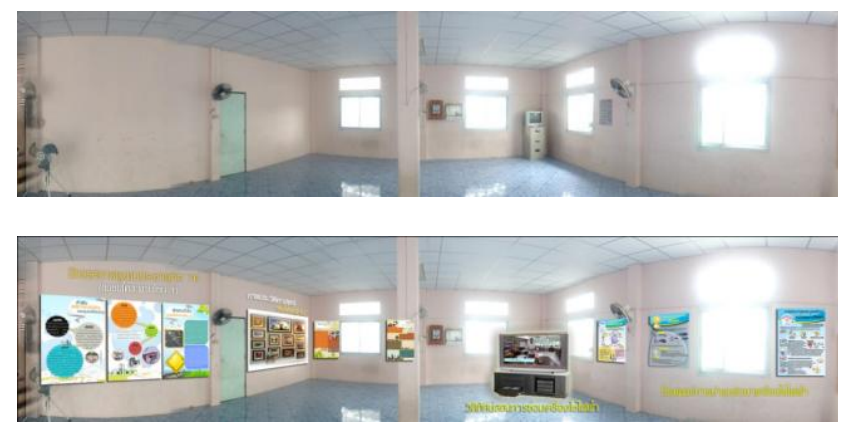

Fig. 2. The learning resource center before and after the development

\section{A. Quality Assessment by the Expert Panel}

The quality of the learning resource for the Saleng community under the bridge of zone 1 entitled "How to Repair Electrical Appliances" could be summarized as below: 
TABLE I. THE QUALITY ASSESSMENT BY THE PANEL OF EXPERTS IN CONTENTS AND EXPERTS IN LEARNING RESOURCE DEVELOPMENT

\begin{tabular}{|l|c|c|c|}
\hline \multirow{2}{*}{\multicolumn{1}{|c|}{ Item }} & \multicolumn{3}{c|}{ Quality Assessment } \\
\cline { 2 - 4 } & Mean & S.D. & Meaning \\
\hline 1. Contents & 4.83 & 0.29 & Very Good \\
\hline $\begin{array}{l}\text { 2. Learning Resource } \\
\text { Development }\end{array}$ & 4.47 & 0.63 & Good \\
\hline
\end{tabular}

According to Table I, the quality assessment in terms of contents was 4.83 with S.D. of 0.29 , or at a very good level. The quality assessment in terms of learning resource development was 4.47 with S.D. of 0.63, or at a good level.

\section{B. Sampling Group's Satisfaction}

The sampling group in this research consisted of 30 itinerant junk buyers who were chosen using specified sampling method who previously participated in the research project entitled "Good-Hearted Vocation Teacher to Support Itinerant Junk Buyers".

TABLE II. The SAMPLING GROUP's SATISFACTION TOWARDS THE LEARNING RESOURCE

\begin{tabular}{|l|c|c|c|}
\hline \multirow{2}{*}{\multicolumn{1}{|c|}{ Item }} & \multicolumn{3}{c|}{ Quality Assessment } \\
\cline { 2 - 4 } & Mean & S.D. & Meaning \\
\hline 1. Video clips & 4.68 & 0.72 & The Highest \\
\hline 2. Posters & 4.71 & 0.63 & The Highest \\
\hline 3. Leaflets & 4.63 & 0.70 & The Highest \\
\hline 4. Exhibition & 4.79 & 0.50 & The Highest \\
\hline \multicolumn{1}{|c|}{ Average } & $\mathbf{4 . 7 0}$ & $\mathbf{0 . 6 4}$ & The Highest \\
\hline
\end{tabular}

According to Table II, , the sampling group's satisfaction towards the learning resource for the Saleng community under the bridge of zone 1 entitled "How to Repair Electrical Appliances" was 4.70 on average with S.D. of 0.64 , or at the highest level.

\section{RESEARCH DISCUSSIONS}

According to the research results, the learning resource for the Saleng community under the bridge of zone 1 entitled "How to Repair Electrical Appliances" contained video clips, posters, leaflets and exhibition in order to increase the understanding entitled "How to Repair Electrical Appliances" which included fans, irons and rice cookers. There was also information about the community. These results could be discussed as follows.

\section{A. The Assessment by the Experts in Contents}

The quality of the learning resource for the Saleng community under the bridge of zone 1 entitled "How to Repair Electrical Appliances" in terms of contents was 4.83 on average with S.D. of 0.29 , or at a very good level. This was because the contents in the learning resource for the Saleng community under the bridge of zone 1 entitled "How to Repair Electrical Appliances" were accurate and suitable for the community. This comment is in accordance with the research study entitled "Community Research Project to Reduce and Solve the Social Inequality in Bangkok: A Case Study of
Community under the Bridge of Zone 1, Toong-kru District, Bangkok" [1]. The contents of this learning resource also complied with the research study entitled "Good-Hearted Vocation Teacher to Support Itinerant Junk Buyers" [2] which was approved at a national level. Therefore, the contents were accurate and complete.

\section{B. The Assessment by the Experts in Learning Resource Development}

The quality of the learning resource for the Saleng community under the bridge of zone 1 entitled "How to Repair Electrical Appliances" in terms of learning resource development was 4.47 on average with S.D. of 0.63 , or at a good level. To accomplish this result, the researchers applied theories about how to create video clips and how to choose the right angle for each context. There were also principles in graphic design and digital publishing and theories about how to run an exhibition in terms of layout and material presentation. The aspect of video clips in this research was in accordance with the research study by Petchthai Kerdchote and Sopa Meeyai [4] who developed the video clips to increase the public relations of the Department of Educational Communications and Technology, Faculty of Industrial Education and Technology, King Mongkut's University of Technology Thonburi and found that their video clips were of good quality and could be used for intended purpose. As for the printing aspect, the quality of the learning resource in this research was at a good level, similar to the research by Weeranan Homdok [5] who researched the publishing set for the public relations of the Masters degree in Educational Technology and Mass Media, because it followed the right approach to publication. Moreover, the quality of the exhibition in this research was at a good level and it was in accordance with the principle of Payungsak Prachusilpa [6] about the exhibition design so that the exhibition could be designed to meet the objectives of the sampling group.

\section{The satisfaction evaluation}

The sampling group of 30 persons showed the highest satisfaction towards the learning resource for the Saleng community under the bridge of zone 1 entitled "How to Repair Electrical Appliances" with mean score of 4.70 and S.D. of 0.64 . This was because the contents of the learning resource for the Saleng community under the bridge of zone 1 entitled "How to Repair Electrical Appliances" were accurate and suitable for the community. The contents would involve the information of the community and how to repair electrical appliances in a step-by-step approach, which is similar to the principle by Narumon Kitpaisarnrattana [7]. To analyse the satisfaction, the data were analysed using SPSS for Windows (Statistical Package for Social Sciences for Windows) and this is similar to the research by Jittima Puttacharoen [8] who examined the learning achievement and the satisfaction towards the webpage contents and found that the sampling group showed the highest level of satisfaction.

\section{Suggestions}

\section{A. Suggestions for application}

1) The learning resource for the Saleng community under the bridge of zone 1 entitled "How to Repair Electrical 
Appliances" could be adopted for the self-study approach aimed at adults outside the formal education system or those without an opportunity to study the specialized discipline.

2) The learning resource for the Saleng community under the bridge of zone 1 entitled "How to Repair Electrical Appliances" could be distributed on an online social network to gain broader usage.

\section{B. Suggestions for further research}

1) There should be research into the development of the learning resource for the Saleng community under the bridge of zone 1 about how to repair cars and household accounting.

2) There should be a study into the factors which affect the learning resource for the Saleng community under the bridge of zone 1 entitled "How to Repair Electrical Appliances" in an online social network environment.

3) The posters could be developed to teach skills in a stepby-step manner.

\section{ACKNOWLEDGMENT}

The development of the learning resource for the Saleng community under the bridge of zone 1 entitled "How to Repair Electrical Appliances" was granted research funding from Faculty of Industrial Education and Technology, King Mongkut's University of Technology Thonburi to support the extension from the previous research with the Saleng community under the bridge of zone 1 .

\section{REFERENCES}

[1] The Research Committee for the Community Research Project, Community Research Project to Reduce and Solve the Social Inequality in Bangkok: A Case Study of Community under the Bridge of Zone 1, Toong-kru District, Bangkok, Photocopied Document, 2011, p. 4.

[2] The Working Team from Faculty of Industrial Education and Technology, Research Project Entitled "Good-Hearted Vocation Teacher to Support Itinerant Junk Buyers", Bangkok, 2013, pp. 4-5.

[3] Head of the Community under the Bridge of Zone 1, Population in the Community under the Bridge of Zone 1, Bangkok, Interview, 12 February, 2013.

[4] P. Kerdchote and S. Meeyai, Research Project Entitled "The Development of Video Clips for Public Relations of the Department of Educational Communications and Technology, Faculty of Industrial Education and Technology, King Mongkut's University of Technology Thonburi, Faculty of Industrial Education and Technology, King Mongkut's University of Technology Thonburi, 2007, p. B.
[5] W. Homdok, Publishing Set for the Public Relations of the Masters Degree in Educational Technology and Mass Media, Faculty of Industrial Education and Technology, King Mongkut's University of Technology Thonburi, 2010, p. B.

[6] P. Prachusilpa, Design for Exhibition, Compact Design, Bangkok, 1992, p. 1.

[7] N. Kitpaisarnrattana, Users' Satisfaction towards 7 Types of Service in Chulalongkorn University Library, a Master's thesis in Communication Arts, Chulalongkorn University, 2002, p. B.

[8] J. Puttacharoen, Learning Achievement and Satisfaction towards Web Pages with Different Contents and Presentation Styles, a Master's thesis in Education, Kasetsart University, 2000, p. B

\section{APPENDIX}
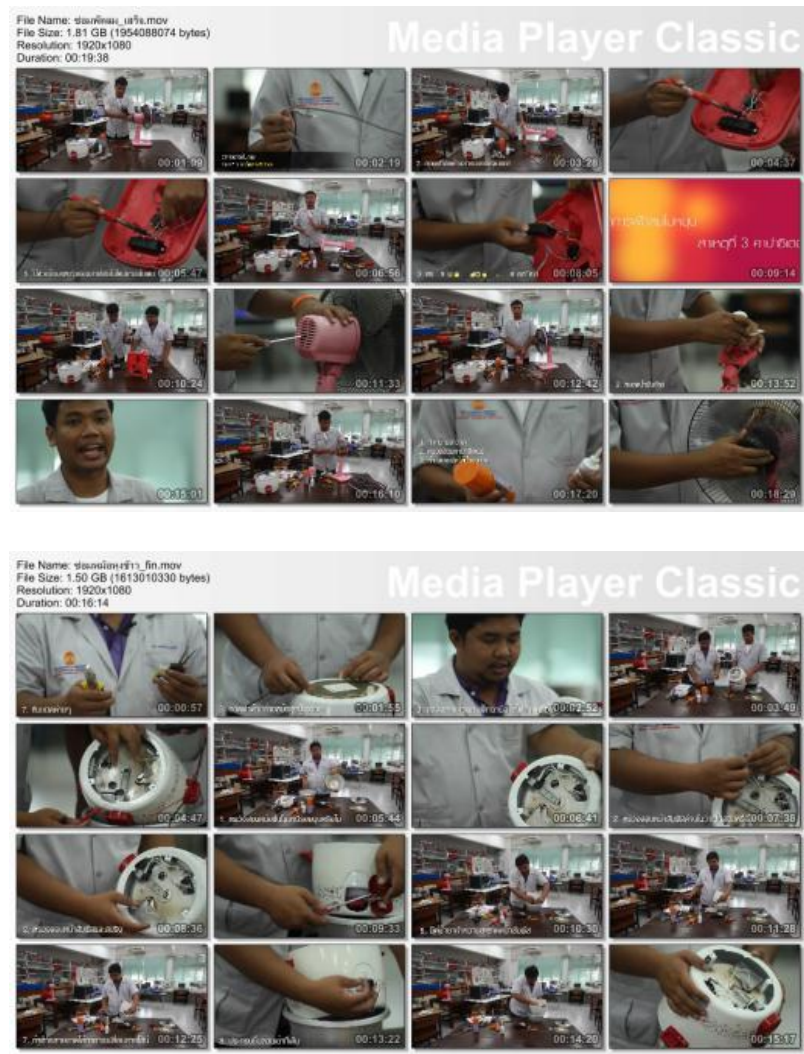

Fig. 3. Video clips entitled "How to Repair Electrical Appliances" and "How to Fix Fans" 